\title{
Cancer Progression Related with Tumor-associated Macrophages
}

\author{
Ethiraj Purushoth ${ }^{1, *}$, Loganathan Tholcopiyan ${ }^{1}$, Arul Santhosh $^{2}$ \\ ${ }^{1}$ Department of Biochemistry, VRR Institute of Biomedical Science (Affiliated to University of Madras), India \\ ${ }^{2}$ Department of Biotechnology, Rajalakshmi Engineering College, India
}

Copyright $(\mathrm{C} 2016$ by authors, all rights reserved. Authors agree that this article remains permanently open access under the terms of the Creative Commons Attribution License 4.0 International License

\begin{abstract}
Tumor-associated macrophages are one of the main populations of inflammatory cells in cancers that favor tumor cell growth and survival. Tumor-derived factors such as VEGF-A and CSF-1 recruit the macrophages in tumor micro environment and alter their phenotype in M1 to M2 or tumor-associated macrophages by secretion of several cytokines including IL-4, IL-13 and VEGF-A. In return tumor-associated macrophages released growth factors and cytokine that helps in cancer cell proliferation and metastasis Tumor-associated macrophage secreted cytokines promotes the angiogenesis and lymphangiogenesis that assist tumor cell to metastasize in distant organs. Importantly, tumor-associated macrophages promote an immunosuppressive environment with the help of other immune cells in the tumor-bearing host that helps tumor to grow unchecked and unchallenged. In addition, tumor-associated macrophages induce resistance against cancer therapy and boost tumor regrowth after therapy. In this review, we discuss the role of tumor-associated macrophages in the pathobiology of cancer. Understanding of the crucial role of tumor-associated macrophages in cancer progression may help to assess potential therapeutic strategies.
\end{abstract}

Keywords Tumor-associated Macrophages, Cancer Progression, Therapy Resistance, Immune Suppression

\section{Introduction}

Cancer remains the most common cause of death in several countries, following cardiovascular diseases [1]. Genetic mutations and deregulated signaling pathways contribute to the development of cancer phenotype that leads to uncontrolled cell growth [2-5]. Growing body of evidence suggest that the Tumor Microenvironment (TME) play crucial role in development and progression of cancer [6-8]. The TME in which tumor exist typically contains a wide variety of cells including malignant and non-malignant cell populations [9]. Non-malignant populations include fibroblasts, stromal cells, bone marrow-derived inflammatory cells and immune cells such as T-cells, natural killer cells and macrophages $[9,10]$. Macrophages are crucial cellular component of TME, where they are commonly termed Tumor-associated Macrophages (TAMs). Macrophages are the key component of innate immunity and perform multiple functions including tissue growth, tissue repair, homeostasis, and both inhibition or promotion of cell proliferation $[11,12]$. Macrophages are first line of defense against invading pathogens as these cells phagocytose microbes and present antigens to T-cells. However, TME alters the phenotype of macrophages from classically activated or M1 macrophages that exhibit inflammatory functions to alternatively activated or M2 macrophages or TAM that exhibit anti-inflammatory functions. TAMs originate from circulating monocytes which infiltrated in TME and programmed by tumor-secreted factors such as vascular endothelial growth factor-A (VEGF-A) and colony-stimulating factor-1 (CSF-1) [13]. TME alters the macrophages to TAM phenotype and induce them toward Tumor-supportive M2-polarized macrophages [14-16]. Tumor supporting functions of TAM includes encouragement of tumor growth by secretion of growth factors and induction of angiogenesis and lymphangiogenesis for metastatic spread [13,17].

In this article, we review the role of TAM in providing favorable conditions for tumor progression. In addition, we have discussed how TAM induced immunosuppression and therapy resistance help unchecked growth and survival of tumor cell. We have listed the tumor-derived factors responsible for macrophage polarization and TAM-derived factors that induce immune suppression and therapy resistance.

\section{The Role of Tumor Associated Macrophage in Cancer Progression}

Recruitment of macrophages and converting them to TAM in the TME is recognized as key features of cancer progression. TAMs have integral role in cancer progression by supporting tumor cell proliferation, survival, angiogenesis, lymphangiogenesis as well as migration and invasion (Fig.1). Furthermore, TAMs guide tumor cells for intravasation of at the primary tumor site and extravasation for distant metastatic [13, 18-20]. Role of TAM in cancer progression is discussed below. 


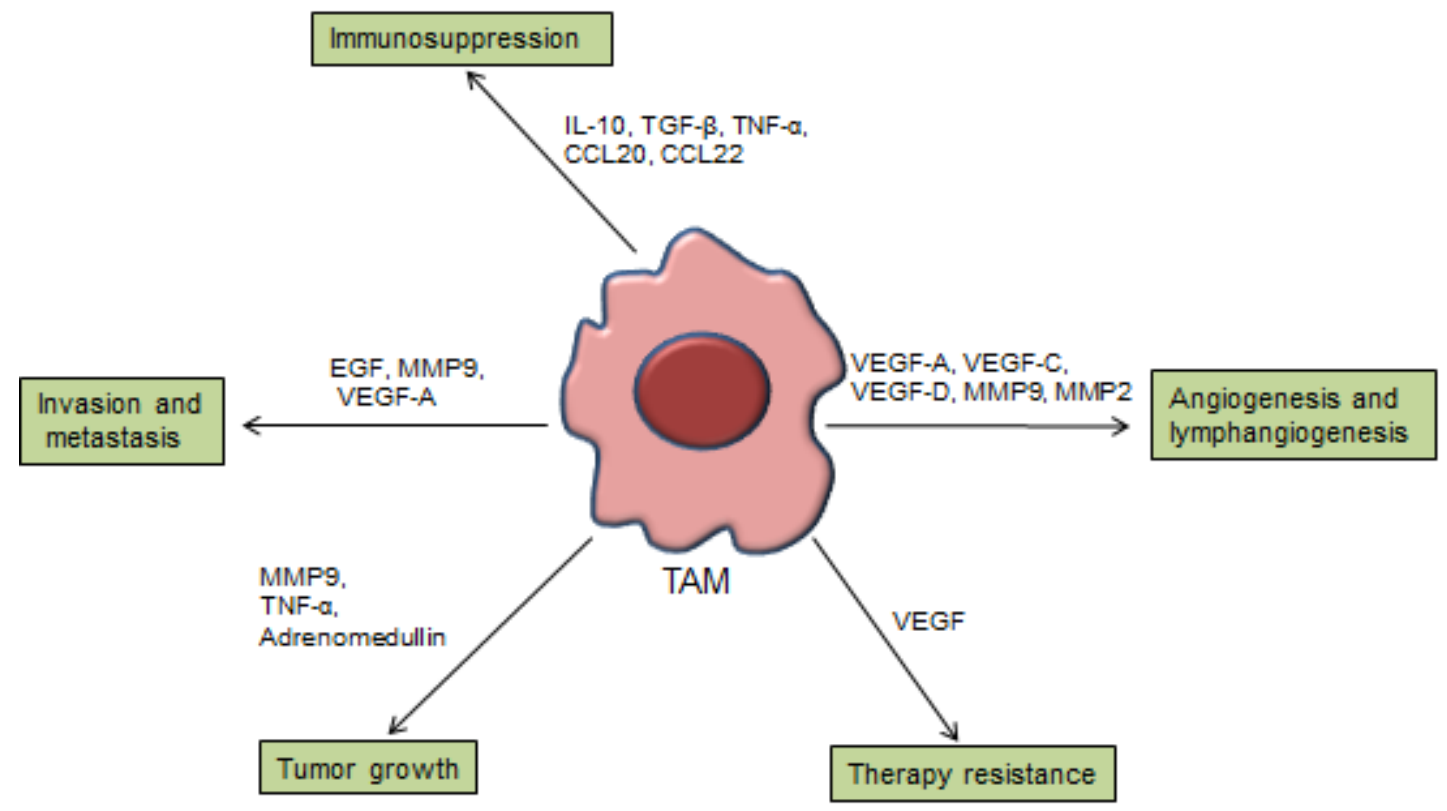

Figure 1. Tumor associated macrophages and cancer progression. Cross-talk between cancer cells and macrophages in TME promotes the polarization of macrophages to TAM or M2 phenotype. In return the TAM secreted factors in TME induce the tumor growth, aggressiveness, immunosuppression and therapy resistance.

\subsection{Tumor Growth}

Unchecked tumor growth is the result of several factors such as altered signaling, continuous supply of growth factors, immune evasion, therapy resistance, and overall change in TME. The presence of TAM is positively correlated with endometrial cancer, breast cancer, and renal cell cancer proliferation [21,22]. TAMs inhibit the cytotoxicity of T-cells and NK cells in TME by secreting large amounts of IL-10 that helps in tumor growth [23]. TAM-derived adrenomedullin is found to induce angiogenesis and tumor growth in melanomas by interacting endothelial cells eNOS signaling pathway [24]. In addition, TAM-derived adrenomedullin activate macrophage also in autocrine manner and inhibition of adrenomedullin receptors on TAMs reduces the angiogenesis and tumor growth $[25,26]$. Co-cultured of macrophages with tumor cells shown to facilitate tumor cell proliferation by secreting several growth factors and cytokine [23]. The cytokine IL-23 that induce inflammatory responses is believed promote tumor growth by upregulating MMP9, that are crucial for tumor growth $[27,28]$. Further, TAMs depletion proven to prevent tumor growth, suggesting its contribution in growth of disease [29]. Activated macrophages are also found to induce chromosomal instability in the bystander cells. Bystander cells are the normal cells that are surrounding the tumor or infected cells. Bystander effects have been studied extensively to both radiation and chemotherapeutic treatment [30-33]. In present scenario, human intestine infection with Enterococcus faecalis activates macrophages that secretes increased TNF- $\alpha$, that acts upon the bystander epithelial cells and induces a pro-proliferation and anti-apoptotic pathways [34]. This result shows the deleterious effects of activated macrophages in the cancer progression.

\subsection{Invasion and Metastasis}

Cancer metastasis is one of the hallmarks of cancer, which leads to the formation of new tumors at distant organ is the major cause of cancer-related death $[35,36]$. Tumor associated macrophages are known to influence the process of metastasis by altering the TME in which tumor exist $[22,37]$. The intravasation of tumor cell is shown to be associated with TAMs in mammary tumors, suggesting its crucial role in cancer metastasis [38]. Macrophages and tumor cells works in coordination to help each other, for example CSF-1 produced by tumor cells promotes macrophage migration and macrophage-derived epidermal growth factor (EGF) promotes tumor cell invasion. Inhibition of CSF-1 or EGF attenuates the migration of macrophages and tumor cells [20]. TAM, derived from lung cancer tissue found to express high level of Cathepsin K, PDGF-A, VEGF-A, COX-2, MMP-9, HGF and UPA. Interestingly, conditioned medium obtained from TAM significantly promoted cell migration and invasion in SPC-A1, A549, and H460 lung cancer cells. Further, anti-MMP-9 and anti-UPA monoclonal antibodies inhibit TAM-induced invasion in lung cancer cells [39]. Further, TME induced signals significantly contribute in the metastasis of tumor cells. Extracellular matrix components in TME have been suggested to alter the functions of TAM that promote the growth and aggressiveness of the tumor cells. Sulfate proteoglycan such as versican shown to be expressed in tumor cells activate macrophages in Lewis lung carcinoma through TLR-2/TLR-6 signaling axis and that leads to growth and aggressiveness of tumor [40]. 
Macrophage produced proteolytic enzymes such as serine proteases, cathepsins and MMPs have been implicated in degradation of the ECM and thereby promoting the cancer cells invasion. Moreover, depletion of TAM produced cathepsin B and S found to inhibit the tumor invasion [41], suggesting the role of TAM in tumor invasion.

\subsection{Angiogenesis and Lymphangiogenesis}

Cancer growth and aggressiveness depend on angiogenesis and lymphangiogenesis triggered by signaling molecules in TME. Continuous supply of nutrients and oxygen by newly formed blood vessels helps in the growth of tumor cells and provide an opportunity to escape into circulation and metastasize to distant organs. TME induced changes in macrophage promotes the secretion of pro-angiogenic factors $[17,27,42]$. Role of TAM in angiogenesis has been demonstrated in several animal models of prostate cancer, breast cancer, ovarian cancer, melanoma and cervical cancer $[27,43,44]$. Although, tumor cell-derived factor are capable to initiate tumor angiogenesis, presence of TAMs expedite the process of angiogenesis [18]. Further, depleting TAMs by clodronate encapsulated reduce blood vessel density in the tumor tissue [45]. Further a positive correlation between the recruitment of TAM and angiogenesis was found in several human cancers including gastric cancer, melanoma, breast cancer, pulmonary adenocarcinoma, B-cell non-Hodgkin's lymphoma and glioma [46-53]. Overexpression of CSF-1 enhances the infiltration of TAMs in TME that induce malignant progression in the mammary epithelium of MMTV-PyMT mice [54]. Further, inhibition of CSF-1 or its receptor with the help of short-interfering RNA (siRNA) in mice model decreased the macrophage infiltration [17,55]. TAM-derived VEGF-A is believed to be a significant contributor in tumor angiogenesis and its level correlates with TAM density $[51,56]$. A subset of TAM that propagate in hypoxic conditions was shown to be associated with VEGF-A and pro-angiogenic gene expression [57]. Further, tumor-released CSF-1 (M-CSF), also induces the VEGF-A expression through NF- $\kappa$ B activation that triggers the pro-angiogenic functions of macrophages [20,58]. In ovarian cancer mouse model, TAM were shown to be a key source of MMP9 and positively correlated with tumor growth and angiogenesis [27]. In addition, enhanced expression of MMP9 in pancreatic cancer TME facilitated the release of VEGF-A [59]. In addition, re-polarization of the TAM to M1 inhibits the pro-angiogenic function and induces the expression of anti-angiogenic factors such as IFN- $\beta$ and CXC-chemokine ligand 9 (CXCL9) [60]. Increased expression of oncogene GLI1 is shown to regulate the macrophages induced angiogenesis in oral cancer [61]. While the inhibition of GLI1 shows a promising anti-cancer therapeutic strategy $[62,63]$, the detailed mechanism by which it regulates the macrophages has to be studied in detail.

It has been demonstrated recently that TAM not only participate in angiogenesis but also in lymphangiogenesis in TME by producing VEGF-A, VEGF-C, VEFG-D and MMP-9 $[64,65]$. TAM expressing VEGF-C, VEGF-D, and VEGFR-3 found to elevate tumor lymphatic microvessel density (LVD) in cervical cancer [65]. VEGF-C released by TAMs plays a significant role in peritumoral lymphangiogenesis and lymphatic metastases in cervical cancer [65]. Further, VEGF-C expression was positively associated with lymphangiogenesis and angiogenesis in bladder cancer (Miyata Y 2006) [66]. Furthermore, TAM expressed lymphatic endothelial growth factors are known to promote lymphangiogenesis $[65,67] . \mathrm{CD} 11 \mathrm{~b}^{+}$macrophages express lymphatic endothelial markers, including LYVE-1 and Prox-1 and shown to contribute in lymphangiogenesis under pathological conditions [68]. Further, TAM produced factors such as VEGF-C has been shown to enhance the intratumoral lymphangiogenesis and regional lymphovascular invasion in breast cancer and mantle cell lymphoma $[69,70]$. Further, TAM demonstrated to induce VEGF-C expression in Lewis lung carcinoma cells [71]. Interestingly inhibition of VEGFR-3 (receptor of VEGF) suppresses tumor lymphangiogenesis and metastasis of tumor to distant organs [72]. In addition, depletion of VEGFR-3 ${ }^{+}$TAM significantly reduces the secretion of VEGF-C, VEGF-D and LVD in TME [73]. VEGF-A not only induce lymphangiogenesis by recruiting macrophages it promotes proliferation and migration of VEGFR-2 expressing lymphatic endothelial cells in a skin cancer model $[74,75]$. Further in fibrosarcoma model, VEGF-A induces peritumoral lymphangiogenesis and participates in lymphatic metastasis [76]. TAM regulates lymphangioegensis, by producing enzymes such as MMPs that control matrix remodeling [77]. MMP-9 and MMP-2 regulates the formation of lymphatic vessels and their downregulation or inhibition reduces lymphangiogenesis, the tube-forming properties and invasive ability of LEC $[78,79]$.

\section{Tumor Associated Macrophage Induce Immunosuppression}

Coordinated action of both innate and adaptive arms of the immune system is essential to induce phagocytosis or apoptosis in tumor cell. Macrophages possess the unique ability of phagocytosis and present tumor antigens to induce adaptive immunity to orchestrate the antitumor immune response. However, an immunosuppressive factor present in the TME alters the antitumor phenotype of macrophage and induces their pro-tumorigenic characteristics that allow tumor immune evasion. Tumor cells escape from immune system is one of critical events that regulate tumor survival, growth, and metastasis. TAM adopts a poor antigen-presenting capability and produce immunosuppressive cytokine such as IL-10 and TGF- $\beta$ that suppress the functions of $\mathrm{T}$ cells [80]. TAM-derived cytokines and proteases, such as IL-10, TGF- $\beta$, and arginase 
1, have reported to contribute in immunosuppression (Fig. 1) [81-83]. TGF- $\beta$ is known to promote tumor-associated macrophage polarization phenotype, which further induce TGF- $\beta$ secretion and deepens immunosuppression [84]. TGF- $\beta$ also inhibits the cytolytic activity of natural killer (NK) cells and decreases dendritic cells (DCs) migration that leads to the poor antitumor response [85-88]. Further, macrophage produced TNF- $\alpha$ and IL-10 induce the expression of programmed cell death 1 (PD-L1) that reduce the $\mathrm{T}$ cell proliferation induce $\mathrm{T}$ cell dysfunction [89]. Moreover, PD-L1 blocking found to enhance the capacity of $\mathrm{T}$ cells to eliminate tumor cells. Regulatory $\mathrm{T}$ cells (Tregs) are commonly found in various tumors and known to counteract $\mathrm{T}$ cell-mediated immune responses [90-93].

Moreover, infiltration of Tregs in tumors is found to be correlated with a lack of responsiveness to therapy [94]. Compelling data demonstrated that Tregs inhibit host T-cell activity against tumor associated antigens and impair efficacy of anticancer immunotherapeutic strategies [95]. Further removal of these cells has been shown to increase the natural anti-tumor T-cell responses [96]. Moreover, depletion of Tregs found to enhance the antitumor immunity in cancer patients [96]. CCL22/CCR4 axis is found to mediate the intratumoral recruitment of Treg [97]. Importantly, TAMs produce the chemokine CCL22 and CCL20, and mediate the trafficking of Tregs in ovarian and colorectal cancer $[92,98,99]$. Further, TGF- $\beta$ promotes $\mathrm{CD}^{+} \mathrm{T}$ cells differentiation into $\mathrm{Th} 2$ cells and reduces the efficacy of efficient antitumor immune response [100]. Moreover, TGF- $\beta$ also reduces the antitumor activity of $\mathrm{CD} 8^{+} \mathrm{T}$ cells by suppressing the expression of several cytolytic genes, such as IFN- $\gamma$, granzyme A, granzyme B, and FAS ligand [85,101]. Furthermore, TGF- $\beta$ also stimulates tumor growth by the maintenance of Treg cell differentiation [85]. In inflammatory TME, TAMs recruit monocytes and other immunosuppressive cells such as Tregs and Myeloid-derived suppressor cells (MDSCs) by secreting several signaling molecules $[99,102]$. MDSCs are diverse population of immature granulocytes, monocytes, and dendritic cells and are known for its ability to inhibit cytotoxic T-cell responses. The secreted factors from TAMs recruit each leukocyte population with the MDSC phenotype. TAM-derived chemokine CCL17 and CCL22 attract CCR4 expressing monocytes, immature dendritic cells, and other lymphocytes in TME and subsequently contribute in the immunosuppression [103].

\section{The Role of Tumor Associated Macrophage in Therapy Resistance}

Growing body of evidence suggest that TAMs modulate the efficacy of several anticancer therapy and facilitate tumor regrowth, and spread after the treatment. Macrophage toxins were shown to reduce the antitumor efficacy of doxorubicin mice bearing immunogenic leukemia or lymphoma [104]. Further, antitumor activity of the taxane docetaxel was found to be enhanced by depletion of TAMs and subsequently activation or expansion of M1-like macrophages in 4T1-Neu mammary tumor implants. In addition, in vitro experiments demonstrated that docetaxel-treated monocytes are able to enhance tumor-specific, cytotoxic T cell responses [105]. Further, Trabectedin; a DNA-damaging agent was shown to inhibit the growth of mouse fibrosarcomas by depleting TAMs, suggesting that the antitumor activity of some cytotoxic agents may depend on their ability to reprogram or deplete protumoral immune cells [105,106]. In addition, inhibition of CSF1R in mouse models of glioblastoma reduces the tumor volume by re-polarizing them to a state regulated by GM-CSF that has been suggested to be anti-tumoral [107]. Similarly CSF1R inhibitors found to deplete TAMs and enhance chemotherapy responses in cervical and breast cancer models [108]. Likewise, TAM depletion improved the efficacy of paclitaxel (PTX, a taxane) in MMTV-PyMT mouse mammary tumors [19]. PTX was found to increase the recruitment of macrophages to the tumors by upregulating the expression of CSF1 that increased TAM numbers in PTX-treated tumors which limits the infiltration of $\mathrm{CD}^{+}$cytotoxic $\mathrm{T}$ cells and possibly decrease their tumoricidal activity. These findings indicate that TAMs can limit the therapeutic efficacy of PTX in breast cancer, by suppressing the antitumor immune responses [19]. Moreover, released lysosomal enzymes, cathepsins B and S, shown to protect tumor cells from PTX-induced cell death and reduce the efficacy of PTX [109]. In addition, gemcitabine and 5-fluorouracil induce monocytes/MDSCs to release cathepsin B [110]. Further, co-culture of macrophage with cancer cells demonstrated that cathepsins protect cancer cells from cytotoxic effects doxorubicin and etoposide [109]. Interestingly, downregulation of TAM-secreted VEGF or placental growth factor (PlGF) decreased vessel leakiness, normalized the vasculature, and enhanced chemotherapy delivery to tumors $[60,111]$. The cytotoxic drugs affect multiple cell types in TME as well as TAM that may influence the function and ability of TAMs to respond to a given chemotherapeutic drug [112]. Furthermore, application of several extracellular bacteria including anaerobe Clostridium and Shigellae, which produce several lethal toxins, were explored for their anti-tumor activities [113-120]. Bacterium Shigellae induced apoptosis shown to deplete TAMs that leads to complete tumor regression in breast cancer model [115]. Few studies correlated the greater numbers of TAM in mouse tumors with poor tumor responses to irradiation [121]. Local irradiation of orthotopic human glioblastoma is shown to enhance the infiltration of $\mathrm{CD}_{11 \mathrm{~b}^{+}}$myeloid cells [122]. In addition, CXCL12 was found to attract the $\mathrm{F} 4 / 80^{+} \mathrm{TIE}^{+}$macrophages in the lung and mammary tumors following irradiation [123]. Further TAM-induced immunosuppression is shown to be correlated with the activation of several transcription factors such as NF-kB, STAT3 and STAT6, however the specific mechanism still unexplored [124]. 


\section{Macrophage Polarization from M1 to M2}

M1 or Classical and M2 or alternative polarization of macrophages, mimic the Th1-Th2 activation of $\mathrm{T}$ cells, denote two opposite functional state of macrophage. Growing body of evidence suggest that M1 phenotype of macrophage is stimulated by pro-inflammatory cytokines such as IFN- $\gamma$, TNF, or microbial products such as TLR ligands that promotes elevated antigen presentation, high secretion of IL-23 and IL-12 and higher level of reactive oxygen intermediates (ROI) and nitric oxide (NO) [125]. Whereas, M2 macrophages are known as resting phenotype which promotes healing-type situations without infections which can be further induced by IL-10, IL-4 or IL-13. Several inflammatory mediators, signaling pathways, and transcription factors participates in the regulation of macrophage polarization. Further, immune cells such as, polarized T cells also participate in macrophage polarization [126]. IFNs and TLR activates STAT1 that promotes macrophage polarization toward the M1 phenotype via STAT/IRF signaling, while activation STAT6 by IL-4 and IL-13 promotes macrophage function toward the M2 phenotype [16]. TLR4 stimulated by lipopolysaccharide (LPS) and other microbial ligands; induce macrophages polarization towards M1 by MyD88 and TRIF signaling pathways which subsequently activates nuclear factor kappa $\mathrm{B}(\mathrm{NF}-\kappa \mathrm{B})$. NF- $\mathrm{NB}$ pathway is known to regulate the expression several inflammatory genes such as IL-6, IL1B, $\mathrm{TNF} \alpha$ and cyclooxygenase 2 (COX2). Further, NF- $\kappa \mathrm{B}$ signaling activates the transcription factor interferon-responsive factor 3 (IRF3), which promotes the expression and secretion of type I interferon, including IFN $\alpha$ and IFN $\beta$ that subsequently activates the transcription factor STAT1. IRF3 and IRF5 are shown to be involved in regulating $\mathrm{M} 1$ polarization and M1-associated gene induction $[127,128]$. Further, IFN induced chemokine such as CXCL9 and CXCL10 are typical characteristic of M1 macrophage [129]. Macrophage polarization is extremely dynamic process that can be reversed under pathological and physiological conditions [130,131]. Macrophages polarization towards M2 phenotype can be induced by IL-4, IL-13, and IL-10 via activation of STAT6 or STAT3 $[132,133]$. In various pathophysiological settings, the similar signaling pathway can switch macrophages to M1 or M2 phenotype. Accumulating data suggest that microRNAs (miRNAs), such as miR-155 and miR-146 also regulate macrophages polarization through TLR4/IL-1R signaling pathways [134-138]. Furthermore, let-7c was found to express at a greater level in M2 than M1-type macrophages. In addition, when M2 macrophages were re-polarized to M1-type macrophages, let-7c expression level was decreased, implicating the role of let-7c in macrophage polarization [139].

\section{Conclusions}

Macrophages are extremely versatile and plastic immune cells that can be altered and perform wide range of functions in TME. Another important pathway to study will be the macrophages associated DNA damages in tumor cells. Macrophages induced production of ROS and NO induces all types of damages including the lethal DNA double strand breaks, which is evident by the increased chromosomal aberrations and $\mathrm{YH} 2 \mathrm{AX}$ [140]. Even though DNA repair proteins like FANCD2, RAD51 [141] try to resolve the damages, it is important to note that the improper repair of macrophages assisted DNA damages will also lead to carcinogenesis and cancer progression. Tumor cell-derived factors highjack the regular functions of macrophages and induce M2 macrophage phenotype that are known as TAM. Macrophage polarization is determined by the inducer that can be cytokine, growth factors or bacterial products. The M2 macrophages are divided into M2a, M2b, M2c and M2d subtypes that functions in tumor promotion, and commonly known as TAMs. Growing body of evidences suggest that TAMs significantly influence the tumor progression, immune suppression and therapy resistance. In the light of this evidence, attempts are being made to target the cytokines and growth factors that polarize M1 macrophages to TAM or M2 in TME. Importantly, repolarization of macrophages from M2 to cytotoxic M1 phenotype hold potential for cancer therapy. The re-education of TAM from M2 to M1 by histidine-rich glycoprotein (HRG), which downregulate macrophage PlGF, promoted normalization of blood vessels, and enhances the efficacy of chemotherapy. Re-programming of macrophages from M2 to M1 can be crucial for effective treatment and to develop novel therapeutics interventions.

\section{REFERENCES}

[1] Ma, X., Yu, H. Global burden of cancer. Yale Journal of Biology and Medicine, 79(3-4):85-94, 2006.

[2] Deshmukh, S.K., Srivastava, S.K., Bhardwaj, A., Singh, A.P., Tyagi, N., Marimuthu, S., Dyess, D.L., Dal Zotto, V., Carter, J.E., Singh, S. Resistin and interleukin-6 exhibit racially-disparate expression in breast cancer patients, display molecular association and promote growth and aggressiveness of tumor cells through STAT3 activation. Oncotarget, 6(13):11231-11241, 2015.

[3] Tyagi, N., Marimuthu, S., Bhardwaj, A., Deshmukh, S.K., Srivastava, S.K., Singh, A.P., McClellan, S., Carter, J.E., Singh, S. p-21 activated kinase 4 (PAK4) maintains stem cell-like phenotypes in pancreatic cancer cells through activation of STAT3 signaling. Cancer Letters, 370(2):260-267 2016. 
[4] Tyagi, N., Bhardwaj, A., Srivastava, S.K., Arora, S., Marimuthu, S., Deshmukh, S.K., Singh, A.P., Carter, J.E., Singh, S. Development and Characterization of a Novel in vitro Progression Model for UVB-Induced Skin Carcinogenesis. Scientific Reports, 5: 13894, 2015.

[5] Tyagi, N., Arora, S., Deshmukh, S.K., Singh, S., Marimuthu, S., Singh, A.P. Exploiting Nanotechnology for the Development of MicroRNA-Based Cancer Therapeutics. Journal of Biomedical Nanotechnology, 12(1):28-42, 2016.

[6] Li, H., Fan, X., Houghton, J. Tumor microenvironment: the role of the tumor stroma in cancer. Journal of Cellular Biochemistry, 101(4):805-815, 2007.

[7] Swartz, M.A., Iida, N., Roberts, E.W., Sangaletti, S., Wong, M.H., Yull, F.E., Coussens, L.M., DeClerck, Y.A. Tumor microenvironment complexity: emerging roles in cancer therapy. Cancer Research, 72(10):2473-2480, 2012

[8] Singh, S.R., Rameshwar, P., Siegel, P. Targeting tumor microenvironment in cancer therapy. Cancer Letters, 7(1):30222-30221 2016

[9] Pollard, J.W. Tumour-educated macrophages promote tumour progression and metastasis. Nature Reviews Cancer, 4(1):71-78, 2004.

[10] Balkwill FR., Capasso M., Hagemann T. The tumor microenvironment at a glance. Journal of Cell Science, 125(23):5591-5596, 2012.

[11] Gordon, S., Martinez, F.O. Alternative activation of macrophages: mechanism and functions. Immunity, 32(5):593-604 2010.

[12] Murray, P.J., Wynn, T.A. Protective and pathogenic functions of macrophage subsets. Nature Reviews Immunology, 11(11):723-737. 2011

[13] Qian, B.Z., Pollard, J.W. Macrophage diversity enhances tumor progression and metastasis. Cell, 141(1):39-51, 2010.

[14] Forssell, J., Oberg, A., Henriksson, M.L., Stenling, R., Jung, A., Palmqvist, R. High macrophage infiltration along the tumor front correlates with improved. Clinical Cancer Research, 13(5):1472-1479, 2007.

[15] Galarneau, H., Villeneuve, J., Gowing, G., Julien, J.P., Vallieres, L. Increased glioma growth in mice depleted of macrophages. Cancer Research, 67(18):8874-8881, 2007.

[16] Sica, A., Mantovani, A. Macrophage plasticity and polarization: in vivo veritas. Journal of Clinical Investigation, 122(3):787-795, 2012.

[17] Lin, E.Y., Li, J.F., Gnatovskiy, L., Deng, Y., Zhu, L., Grzesik, D.A., Qian, H., Xue, X.N., Pollard, J.W. Macrophages regulate the angiogenic switch in a mouse model of breast cancer. Cancer Research, 66(23):11238-11246, 2006

[18] Bingle, L., Brown, N.J., Lewis, C.E. The role of tumour-associated macrophages in tumour progression: implications for new anticancer therapies. Journal of Pathology, 196(3):254-265, 2002.

[19] DeNardo, D.G., Barreto, J.B., Andreu, P., Vasquez, L., Tawfik, D., Kolhatkar, N., Coussens, L.M. CD4(+) T cells regulate pulmonary metastasis of mammary carcinomas by enhancing. Cancer Cell, 16(2):91-102, 2009.

[20] Wyckoff, J., Wang, W., Lin, E.Y., Wang, Y., Pixley, F.,
Stanley, E.R., Graf, T., Pollard, J.W., Segall, J., Condeelis, J. A paracrine loop between tumor cells and macrophages is required for tumor cell migration in mammary tumors. Cancer Research, 64(19):7022-7029, 2004.

[21] Tsutsui, S., Yasuda, K., Suzuki, K., Tahara, K., Higashi, H., Era, S. Macrophage infiltration and its prognostic implications in breast cancer: the relationship with VEGF expression and microvessel density. Oncology Reports, 14(2):425-431 2005.

[22] Lewis, C.E., Pollard, J.W. Distinct role of macrophages in different tumor microenvironments. Cancer Research, 66(2):605-612, 2006.

[23] Guruvayoorappan, C. Tumor versus tumor-associated macrophages: how hot is the link? Integrative Cancer Therapies, 7(2):90-95, 2008.

[24] Chen, P., Huang, Y., Bong, R., Ding, Y., Song, N., Wang, X., Song, X., Luo, Y. Tumor-associated macrophages promote angiogenesis and melanoma growth via adrenomedullin in a paracrine and autocrine manner. Clinical Cancer Research, 17(23):7230-7239, 2011.

[25] Brekhman, V., Lugassie, J., Zaffryar-Eilot, S., Sabo, E., Kessler, O., Smith, V., Golding, H., Neufeld, G. R. Receptor activity modifying protein- 3 mediates the protumorigenic activity of lysyl oxidase-like protein-2. Faseb Journal, 25(1):55-65. 2011.

[26] Kaafarani, I., Fernandez-Sauze, S., Berenguer, C., Chinot, O., Delfino, C., Dussert, C., Metellus, P., Boudouresque, F., Mabrouk, K., Grisoli, F., Figarella-Branger, D., Martin, P.M., Ouafik, L. Targeting adrenomedullin receptors with systemic delivery of neutralizing antibodies inhibits tumor angiogenesis and suppresses growth of human tumor xenografts in mice. Faseb Journal, 23(10):3424-3435, 2009.

[27] Huang. S., Van Arsdall, M., Tedjarati, S., McCarty, M., Wu, W., Langley, R., Fidler, I.J. Contributions of stromal metalloproteinase-9 to angiogenesis and growth of human ovarian carcinoma in mice. Journal of the National Cancer Institute, 94(15):1134-1142, 2002.

[28] Erreni, M., Mantovani, A., Allavena, P. Tumor-associated Macrophages (TAM) and Inflammation in Colorectal Cancer. Cancer Microenvironment, 4(2):141-154, 2011.

[29] Polverini, P.J., Leibovich, S.J. Effect of macrophage depletion on growth and neovascularization of hamster buccal pouch carcinomas. Journal of Oral Pathology, 16(9):436-441, 1987.

[30] Chinnadurai, M., Chidambaram, S., Ganesan, V., Baraneedharan, U., Sundaram, L., Paul, S.F., Venkatachalam, P. Bleomycin, neocarzinostatin and ionisingradiation-induce $\mathrm{d}$ bystander effects in normal diploid human lung fibroblasts, bone marrow mesenchymal stem cells, lung adenocarcinoma cells and peripheral blood lymphocytes. International Journal of Radiation Biology, 87(7):673-682, 2011.

[31] Chinnadurai, M., Paul, S.F., Venkatachalam, P. The effect of growth architecture on the induction and decay of bleomycin and X-ray-induced bystander response and genomic instability in lung adenocarcinoma cells and blood lymphocytes. International Journal of Radiation Biology, 89(2):69-78, 2013.

[32] Basheerudeen, S.A., Mani, C., Kulkarni, M.A., Pillai, K., Rajan, A., Venkatachalam, P. Human brain glioblastoma cells 
do not induce but do respond to the bleomycin-induced bystander response from lung adenocarcinoma cells. Mutation Research, 757(2):114-119, 2013.

[33] Chinnadurai, M., Rao, BS., Deepika, R., Paul, S.F.D., Venkatachalam, P. Role of reactive oxygen species and nitric oxide in mediating chemotherapeutic drug induced bystander response in human cancer cells exposed in-vitro. World Journal of Oncology, 3(2):64-72, 2013.

[34] Yang, Y., Wang, X., Moore, D.R., Lightfoot, S.A., Huycke, M.M. TNF-alpha mediates macrophage-induced bystander effects through Netrin-1. Cancer Research, 72(20):5219-5229, 2012.

[35] Hanahan D., Weinberg, R.A. Hallmarks of cancer: the next generation. Cell, 144(5):646-674, 2011.

[36] Khan, N., Mukhtar H. Cancer and metastasis: prevention and treatment by green tea. Cancer and Metastasis Reviews, 29(3):435-445, 2010.

[37] Sangaletti, S., Di Carlo, E., Gariboldi, S., Miotti, S., Cappetti, B., Parenza, M., Rumio, C., Brekken, R.A., Chiodoni, C., Colombo, M.P. Macrophage-derived SPARC bridges tumor cell-extracellular matrix interactions toward metastasis. Cancer Research, 68(21):9050-9059, 2008.

[38] Wyckoff, J.B., Wang, Y., Lin, E.Y., Li, J.F., Goswami, S., Stanley, E.R., Segall, J.E., Pollard, J.W., Condeelis, J. Direct visualization of macrophage-assisted tumor cell intravasation in mammary. Cancer Research, 67(6):2649-2656, 2007.

[39] Wang, R., Zhang, J., Chen, S., Lu, M., Luo, X., Yao, S., Liu, S., Qin, Y., Chen, H. Tumor-associated macrophages provide a suitable microenvironment for non-small Lung Cancer invasion and progression. Lung Cancer, 74(2):188-196, 2011.

[40] Kim, S., Takahashi, H., Lin, W.W., Descargues, P., Grivennikov, S., Kim, Y., Luo, J.L., Karin, M. Carcinoma-produced factors activate myeloid cells through TLR2 to stimulate metastasis. Nature, 457(7225):102-106, 2009.

[41] Gocheva V., Wang HW., Gadea BB., Shree T., Hunter KE., Garfall AL., Berman T., Joyce JA. IL-4 induces cathepsin protease activity in tumor-associated macrophages topromote cancer growth and invasion. Genes \& Development, 24(3):241-255. 2010.

[42] Du, R., Lu, K.V., Petritsch, C., Liu, P., Ganss, R., Passegue, E., Song, H., Vandenberg, S., Johnson, R.S., Werb, Z., Bergers, G. HIF1alpha induces the recruitment of bone marrow-derived vascular modulatory cells to regulate tumor angiogenesis and invasion. Cancer Cell, 13(3):206-220, 2008.

[43] Egami, K., Murohara, T., Shimada, T., Sasaki, K., Shintani, S., Sugaya, T., Ishii, M., Akagi, T., Ikeda, H., Matsuishi, T., Imaizumi, T. Role of host angiotensin II type 1 receptor in tumor angiogenesis and growth. Journal of Clinical Investigation, 112(1):67-75, 2003.

[44] Giraudo, E., Inoue, M., Hanahan, D. An amino-bisphosphonate targets MMP-9-expressing macrophages and angiogenesis to impair cervical carcinogenesis. Journal of Clinical Investigation, 114(5):623-633, 2004.

[45] Zeisberger, S.M., Odermatt, B., Marty, C., Zehnder-Fjallman, A.H., Ballmer-Hofer, K., Schwendener, R.A.

Clodronate-liposome-mediated depletion of tumour-associat ed macrophages: a new and highly effective antiangiogenic therapy approach. British Journal of Cancer, 95(3):272-281, 2006.

[46] Leek, R.D., Lewis, C.E., Whitehouse, R., Greenall, M., Clarke, J., Harris, A.L. Association of macrophage infiltration with angiogenesis and prognosis in invasive breast carcinoma. Cancer Research, 56(20):4625-4629, 1996.

[47] Nishie A., Ono M., Shono T., Fukushi J., Otsubo M., Onoue H., Ito Y., Inamura T., Ikezaki K., Fukui M., Iwaki T., Kuwano M. Macrophage infiltration and heme oxygenase-1 expression correlate with angiogenesis in human gliomas. Clinical Cancer Research, 5(5):1107-1113, 1999.

[48] Takanami, I., Takeuchi, K., Kodaira, S. Tumor-associated macrophage infiltration in pulmonary adenocarcinoma: association with angiogenesis and poor prognosis. Oncology, 57(2):138-142, 1999.

[49] Vacca, A., Ribatti, D., Ruco, L., Giacchetta, F., Nico, B., Quondamatteo, F., Ria, R., Iurlaro, M., Dammacco, F. Angiogenesis extent and macrophage density increase simultaneously with pathological progression in B-cell non-Hodgkin's lymphomas. British Journal of Cancer, 79(5-6):965-970, 1999.

[50] Torisu, H., Ono, M., Kiryu, H., Furue, M., Ohmoto, Y., Nakayama, J., Nishioka, Y., Sone, S., Kuwano, M. Macrophage infiltration correlates with tumor stage and angiogenesis in human malignant melanoma: possible involvement of TNFalpha and IL-1alpha. International Journal of Cancer, 85(2):182-188, 2000.

[51] Shieh, Y.S., Hung, Y.J., Hsieh, C.B., Chen, J.S., Chou, K.C., Liu, S.Y. Tumor-Associated Macrophage Correlated with Angiogenesis and Progression of Mucoepidermoid Carcinoma of Salivary Glands. Annals of Surgical Oncology, 16(3):751-760, 2009.

[52] Espinosa, I., Edris, B., Lee, C.H., Cheng, H.W., Gilks, C.B., Wang, Y., Montgomery, K.D., Varma, S., Li, R., Marinelli, R.J., West, R.B., Nielsen, T., Beck, A.H., van de Rijn, M. CSF1 expression in nongynecological leiomyosarcoma is associated with increased tumor angiogenesis. American Journal of Pathology, 179(4):2100-2107, 2011.

[53] Wu, H., Xu, J.B., He, Y.L., Peng, J.J., Zhang, X.H., Chen, C.Q., Li, W., Cai, S.R. Tumor-associated macrophages promote angiogenesis and lymphangiogenesis of gastric cancer. Journal of Surgical Oncology, 106(4):462-468, 2012.

[54] Aharinejad, S., Sioud, M., Lucas, T., Abraham, D. Target validation using RNA interference in solid tumors. Methods in Molecular Biology, 361:227-238, 2007.

[55] Lin, E.Y., Nguyen, A.V., Russell, R.G., Pollard, J.W. Colony-stimulating factor 1 promotes progression of mammary tumors to malignancy. Journal of Experimental Medicine, 193(6):727-740, 2001.

[56] Valkovic, T., Dobrila, F., Melato, M., Sasso, F., Rizzardi, C., Jonjic, N. Correlation between vascular endothelial growth factor, angiogenesis, and tumor-associated macrophages in invasive ductal breast carcinoma. Virchows Arch, 440(6):583-588. 2002.

[57] Laoui, D., Van Overmeire, E., Di Conza, G., Aldeni, C., Keirsse, J., Morias, Y., Movahedi, K., Houbracken, I., Schouppe, E., Elkrim, Y., Karroum, O., Jordan, B., Carmeliet, P., Gysemans, C., De Baetselier, P., Mazzone, M., Van Ginderachter, J.A. Tumor hypoxia does not drive 
differentiation of tumor-associated macrophages but Rather Fine-Tunes the M2-like Macrophage Population. Cancer Research, 74(1):24-30, 2014.

[58] Eubank, T.D., Roda, J.M., Liu, H., O' Neil, T., Marsh, C.B. Opposing roles for HIF-1alpha and HIF-2alpha in the regulation of angiogenesis by mononuclear phagocytes. Blood 117(1):323-332. 2011.

[59] Bergers, G., Brekken, R., McMahon, G., Vu, T.H., Itoh, T., Tamaki, K., Tanzawa, K., Thorpe, P., Itohara, S., Werb, Z., Hanahan, D. Matrix metalloproteinase-9 triggers the angiogenic switch during carcinogenesis. Nature Cell Biology, 2(10):737-744, 2000.

[60] Rolny, C., Mazzone, M., Tugues, S., Laoui, D., Johansson, I., Coulon, C., Squadrito, M.L., Segura, I., Li, X., Knevels, E., Costa, S., Vinckier, S., Dresselaer, T., Akerud, P., De Mol, M., Salomaki, H., Phillipson, M., Wyns, S., Larsson, E., Buysschaert, I., Botling, J., Himmelreich, U., Van Ginderachter, J.A., De Palma, M., Dewerchin, M., Claesson-Welsh, L., Carmeliet, P. HRG inhibits tumor growth and metastasis by inducing macrophage polarization and vessel normalization through downregulation of PIGF. Cancer Cell, 19(1):31-44, 2011.

[61] Valverde, L.F., Pereira, T.A., Dias, R.B., Guimaraes, V.S., Ramos, E.A., Santos, J.N., Gurgel Rocha, C.A. Macrophages and endothelial cells orchestrate tumor-associated angiogenesis in oral cancer via hedgehog pathway activation. Tumour Biology, 15(7):15, 2016.

[62] Palle, K., Mani, C., Tripathi, K., Athar, M. Aberrant GLI1 Activation in DNA Damage Response, Carcinogenesis and Chemoresistance. Cancers, 7(4):2330-2351, 2015.

[63] Tripathi, K., Mani, C., Barnett, R., Nalluri, S., Bachaboina, L., Rocconi, RP., Athar, M., Owen, L.B., Palle, K. Gli1 protein regulates the S-phase checkpoint in tumor cells via Bid protein, and its inhibition sensitizes to DNA topoisomerase 1 inhibitors. Journal of Biological Chemistry, 289(45):31513-3 $1525,2014$.

[64] Ran, S., Montgomery, K.E. Macrophage-mediated lymphangiogenesis: the emerging role of macrophages as lymphatic endothelial progenitors. Cancers, 4(3):618-657, 2012.

[65] Schoppmann, S.F., Birner, P., Stockl, J., Kalt, R., Ullrich, R., Caucig, C., Kriehuber, E., Nagy, K., Alitalo, K., Kerjaschki, D. Tumor-associated macrophages express lymphatic endothelial growth factors and are related to peritumoral lymphangiogenesis. American Journal of Pathology, 161(3):947-956, 2002

[66] Miyata, Y., Ohba, K., Kanda, S., Nomata, K., Eguchi, J., Hayashi, T., Kanetake, H. The prostaglandin E2 receptor, EP4 receptor (EP4R), plays an important role in the development of transitional cell carcinoma of the upper urinary tract. Virchows Arch 448(6):822-829, 2006.

[67] Ji, R.C. Lymphatic endothelial cells, tumor lymphangiogenesis and metastasis: New insights into intratumoral and peritumoral lymphatics. Cancer Metastasis Review 25(4):677-694 2006.

[68] Maruyama, K., Ii, M., Cursiefen, C., Jackson, D.G., Keino, H., Tomita, M., Van Rooijen, N., Takenaka, H., D' Amore, P.A., Stein-Streilein, J., Losordo, D.W., Streilein, J.W. Inflammation-induced lymphangiogenesis in the cornea arises from CD11b-positive. Journal of Clinical Investigation,
115(9):2363-2372, 2005.

[69] Skobe, M., Hawighorst, T., Jackson, D.G., Prevo, R., Janes, L., Velasco, P., Riccardi, L., Alitalo, K., Claffey, K., Detmar, $\mathrm{M}$. Induction of tumor lymphangiogenesis by VEGF-C promotes breast cancer metastasis. Nature Medicine, 7(2):192-198, 2001

[70] Song, K., Herzog, B.H., Sheng, M., Fu, J., McDaniel, J.M., Chen, H., Ruan, J., Xia, L. Lenalidomide inhibits lymphangiogenesis in preclinical models of mantle cell lymphoma. Cancer Research, 73(24):7254-7264, 2013.

[71] Zhang, J.L., Chen, G.W., Liu, Y.C., Wang, P.Y., Wang, X., Wan, Y.L., Zhu, J., Gao, H.Q., Yin J., Wang, W., Tian, M.L. Secreted Protein Acidic and Rich in Cysteine (SPARC) Suppresses Angiogenesis by Down-Regulating the Expression of VEGF and MMP-7 in Gastric Cancer. PLoS One, 7(9):5, 2012.

[72] Roberts, N., Kloos, B., Cassella, M., Podgrabinska, S., Persaud, K., Wu, Y., Pytowski, B., Skobe, M. Inhibition of VEGFR-3 activation with the antagonistic antibody more potently suppresses lymph node and distant metastases than inactivation of VEGFR-2. Cancer Research, 66(5):2650-2657 2006.

[73] Yang, H., Kim, C., Kim, M.J., Schwendener, R.A., Alitalo, K., Heston, W., Kim, I., Kim, W.J., Koh, G.Y. Soluble vascular endothelial growth factor receptor-3 suppresses lymphangiogenesis and lymphatic metastasis in bladder cancer. Molecular Cancer, 10:1476-4598, 2011.

[74] Hong, Y.K., Lange-Asschenfeldt, B., Velasco, P., Hirakawa, S., Kunstfeld, R., Brown, L.F., Bohlen, P., Senger, D.R., Detmar, M. VEGF-A promotes tissue repair-associated lymphatic vessel formation via VEGFR-2. Faseb Journal, 18(10):1111-1113, 2004.

[75] Hirakawa, S., Kodama, S., Kunstfeld, R., Kajiya, K., Brown, L.F., Detmar, M. VEGF-A induces tumor and sentinel lymph node lymphangiogenesis and promotes lymphatic metastasis. Journal of Experimental Medicine, 201(7):1089-1099, 2005.

[76] Bjorndahl, M.A., Cao, R., Burton, J.B., Brakenhielm, E., Religa, P., Galter, D., Wu, L., Cao, Y. Vascular endothelial growth factor-a promotes peritumoral lymphangiogenesis and lymphatic metastasis. Cancer Research, 65(20):9261-92 68,2005

[77] Allavena, P., Sica, A., Solinas, G., Porta, C., Mantovani, A. The inflammatory micro-environment in tumor progression: the role of tumor-associated macrophages. Critical Reviews in Oncology Hematology, 66(1):1-9, 2008.

[78] Nakamura, E.S., Koizumi, K., Kobayashi, M., Saiki, I. Inhibition of lymphangiogenesis-related properties of murine lymphatic. Cancer Science, 95(1):25-31, 2004.

[79] Detry. B., Erpicum. C., Paupert. J., Blacher. S., Maillard. C., Bruyere. F., Pendeville. H., Remacle. T., Lambert. V., Balsat. C., Ormenese. S., Lamaye. F., Janssens. E., Moons. L., Cataldo, D., Kridelka. F., Carmeliet, P., Thiry. M., Foidart, JM., Struman, I., Noel, A. Matrix metalloproteinase-2 governs lymphatic vessel formation as an interstitial collagenase. Blood, 119(21):5048-5056, 2012.

[80] Kryczek, I., Zou, L., Rodriguez, P., Zhu, G., Wei, S., Mottram, P., Brumlik, M., Cheng, P., Curiel, T., Myers, L., Lackner A., Alvarez X., Ochoa A., Chen L., Zou W. B7-H4 expression identifies a novel suppressive macrophage population in 
human. Journal of Experimental Medicine, 203(4):871-881, 2006.

[81] Kurte, M., Lopez, M., Aguirre, A., Escobar, A., Aguillon, J.C., Charo, J., Larsen, C.G., Kiessling, R., Salazar-Onfray, F. A synthetic peptide homologous to functional domain of human IL-10 down-regulates expression of MHC class I and Transporter associated with Antigen Processing 1/2 in human melanoma cells. Journal of Immunology, 173(3):1731-1737, 2004.

[82] Ben-Baruch, A. Inflammation-associated immune suppression in cancer: the roles played by cytokines, chemokines and additional mediators. Seminars in Cancer Biology, 16(1): 38-52, 2006.

[83] Bak, S.P., Alonso, A., Turk, M.J., Berwin, B. Murine ovarian cancer vascular leukocytes require arginase-1 activity for $\mathrm{T}$ cell suppression. Molecular Immunology, 46(2):258-268, 2008.

[84] Mantovani, A., Sica. A. Macrophages, innate immunity and cancer: balance, tolerance, and diversity. Current Opinion in Immunology, 22(2):231-237, 2010.

[85] Flavell, R.A., Sanjabi, S., Wrzesinski, S.H., Licona-Limon, P. The polarization of immune cells in the tumour environment by TGFbeta. Nature Reviews Immunology, 10(8):554-567. 2010.

[86] Castriconi, R., Cantoni, C., Della Chiesa, M., Vitale, M., Marcenaro, E., Conte, R., Biassoni, R., Bottino, C., Moretta, L., Moretta, A. Transforming growth factor beta 1 inhibits expression of NKp30 and NKG2D receptors: consequences for the NK-mediated killing of dendritic cells. Proceedings of the National Academy of Sciences U S A, 100(7):4120-4125, 2003.

[87] Ito, M., Minamiya, Y., Kawai, H., Saito, S., Saito, H., Nakagawa, T., Imai, K., Hirokawa, M., Ogawa, J. Tumor-derived TGFbeta-1 induces dendritic cell apoptosis in the sentinel lymph node. Journal of Immunology, 176(9):5637-5643, 2006.

[88] Weber, F., Byrne, S.N., Le, S., Brown, D, A., Breit, S.N., Scolyer, R.A., Halliday GM. Transforming growth factor-betal immobilises dendritic cells within skin tumours. Cancer Immunology, Immunotherapy, 54(9):898-906, 2005.

[89] Kuang, D.M., Zhao, Q., Peng, C., Xu, J., Zhang, J.P., Wu, C., Zheng, L. Activated monocytes in peritumoral stroma of hepatocellular carcinoma foster immune privilege and disease progression through PD-L1. Journal of Experimental Medicine, 206(6):1327-1337, 2009.

[90] Bates, G.J., Fox, S.B., Han, C., Leek, R.D., Garcia, J.F., Harris, A.L., Banham, A.H. Quantification of regulatory T cells enables the identification of high-risk breast cancer patients and those at risk of late relapse. Journal of Clinical Oncology, 24 (34):5373-5380, 2006.

[91] Gobert, M., Treilleux, I., Bendriss-Vermare, N., Bachelot, T., Goddard-Leon, S., Arfi ,V., Biota, C., Doffin, A.C., Durand, I., Olive, D., Perez, S., Pasqual, N., Faure, C., Ray-Coquard I., Puisieux, A., Caux, C., Blay, J.Y., Menetrier-Caux C. Regulatory $\mathrm{T}$ cells recruited through CCL22/CCR4 are selectively activated in lymphoid infiltrates surrounding primary breast tumors and lead to an adverse clinical outcome. Cancer Research, 69(5):2000-2009, 2009.

[92] Curiel, T.J., Coukos, G., Zou, L., Alvarez, X., Cheng, P.,
Mottram, P., Evdemon-Hogan, M., Conejo-Garcia, J.R., Zhang, L., Burow, M., Zhu, Y., Wei, S., Kryczek, I., Daniel, B., Gordon, A., Myers, L., Lackner, A., Disis, M.L., Knutson, K.L., Chen, L., Zou, W. Specific recruitment of regulatory T cells in ovarian carcinoma fosters immune privilege and predicts reduced survival. Nature Medicine, 10(9):942-949, 2004.

[93] Ishida, T., Ishii, T., Inagaki, A., Yano, H., Komatsu, H., Iida, S., Inagaki, H., Ueda, R. Specific recruitment of CC chemokine receptor 4-positive regulatory T cells in Hodgkin lymphoma fosters immune privilege. Cancer Research, 66(11):5716-5722, 2006.

[94] Elkord, E., Shablak, A., Stern, P.L., Hawkins, R.E. 5T4 as a target for immunotherapy in renal cell carcinoma. Expert Review of Anticancer Therapy, 9(12):1705-1709, 2009.

[95] Elkord, E., Alcantar-Orozco, E.M., Dovedi, S.J., Tran, D.Q., Hawkins, R.E., Gilham, D.E. T regulatory cells in cancer: recent advances and therapeutic potential. Expert Opinion on Biological Therapy, 10(11):1573-1586, 2010.

[96] Ha, T.Y. The role of regulatory $\mathrm{T}$ cells in cancer. Immune Network, 9(6):209-235, 2009.

[97] Iellem, A., Mariani, M., Lang, R., Recalde, H., Panina-Bordignon, P., Sinigaglia, F., D'Ambrosio, D. Unique chemotactic response profile and specific expression of chemokine receptors CCR4 and CCR8 by CD4(+)CD25(+) regulatory $\mathrm{T}$ cells. Journal of Experimental Medicine, 194(6):847-853, 2001.

[98] Mizukami, Y., Kono, K., Kawaguchi, Y., Akaike, H., Kamimura, K., Sugai, H., Fujii, H. CCL17 and CCL22 chemokines within tumor microenvironment are related toaccumulation of Foxp3+ regulatory T cells in gastric cancer. International Journal of Cancer, 122(10):2286-2293, 2008.

[99] Liu, J., Zhang, N., Li, Q., Zhang, W., Ke, F., Leng, Q., Wang, H., Chen, J., Wang, H. Tumor-associated macrophages recruit CCR6+ regulatory $\mathrm{T}$ cells and promote the development of colorectal cancer via enhancing CCL20 production in mice. PLoS One, 6(4):0019495, 2011.

[100] Maeda, H., Shiraishi, A. TGF-beta contributes to the shift toward Th2-type responses through direct and IL-10-mediated pathways in tumor-bearing mice. Journal of Immunology, 156(1):73-78, 1996.

[101] Thomas, D.A., Massague, J. TGF-beta directly targets cytotoxic $\mathrm{T}$ cell functions during tumor evasion of immune surveillance. Cancer Cell, 8(5):369-380, 2005.

[102] Williams, C.B., Yeh, E.S., Soloff, A.C. Tumor-associated macrophages: unwitting accomplices in breast cancer malignancy. NPJ Breast Cancer 2. 2016.

[103] Mantovani, A., Allavena, P., Sozzani, S., Vecchi, A., Locati, M., Sica A. Chemokines in the recruitment and shaping of the leukocyte infiltrate of tumors. Seminars in Cancer Biology, 14(3): 155-160, 2004

[104] Mantovani, A., Polentarutti, N., Luini, W., Peri, G., Spreafico, F. Role of Host Defense Mechanisms in the Antitumor Activity of Adriamycin and Daunomycin in Mice. Journal of the National Cancer Institute, 63(1):61-66, 1979.

[105] Kodumudi, K.N., Woan, K., Gilvary, D.L., Sahakian, E., Wei, S., Djeu, J.Y. A novel chemoimmunomodulating property of docetaxel: suppression of myeloid-derived suppressor cells in 
tumor bearers. Clinical Cancer Research, 16(18):4583-4594, 2010.

[106] Germano, G., Frapolli, R., Belgiovine, C., Anselmo, A., Pesce, S., Liguori, M., Erba, E., Uboldi, S., Zucchetti, M., Pasqualini, F., Nebuloni, M., van Rooijen, N., Mortarini, R., Beltrame, L., Marchini, S., Fuso, Nerini, I., Sanfilippo, R., Casali, P.G., Pilotti, S., Galmarini, C.M., Anichini, A., Mantovani, A., D' Incalci, M., Allavena, P. Role of macrophage targeting in the antitumor activity of trabectedin. Cancer Cell, 23(2):249-262, 2013.

[107] Quail, D.F., Joyce, J.A. Microenvironmental regulation of tumor progression and metastasis. Nature Medicine, 19(11):1423-1437, 2013.

[108] Strachan, D.C., Ruffell, B., Oei, Y., Bissell, M.J., Coussens, L.M., Pryer, N., Daniel, D. CSF1R inhibition delays cervical and mammary tumor growth in murine models by attenuating the turnover of tumor-associated macrophages and enhancing infiltration by $\mathrm{CD} 8+\mathrm{T}$ cells. Oncoimmunology, 2(12):4, 2013.

[109] Shree, T., Olson, O.C., Elie, B.T., Kester, J.C., Garfall, A.L., Simpson, K., Bell-McGuinn, K.M., Zabor, E.C., Brogi, E., Joyce, J.A. Macrophages and cathepsin proteases blunt chemotherapeutic response in breast cancer. Genes \& Development, 25(23):2465-2479, 2011.

[110] Bruchard M., Mignot G., Derangere V., Chalmin F., Chevriaux A., Vegran F., Boireau W., Simon B., Ryffel B., Connat JL., Kanellopoulos J., Martin F., Rebe C., Apetoh L., Ghiringhelli F. Chemotherapy-triggered cathepsin B release in myeloid-derived suppressor cells activates the Nlrp3 inflammasome and promotes tumor growth. Nature Medicine, 19(1):57-64. 2013.

[111] Stockmann, C., Doedens, A., Weidemann, A., Zhang, N., Takeda, N., Greenberg, J.I., Cheresh, D.A., Johnson, R.S. Deletion of vascular endothelial growth factor in myeloid cells accelerates tumorigenesis. Nature, 456(7223):814-818. 2008.

[112] Coussens, L.M., Zitvogel, L., Palucka, A.K. Neutralizing tumor-promoting chronic inflammation: a magic bullet? Science, 339(6117):286-291, 2013.

[113] Gao, Z., Xu, X., McClane, B., Zeng, Q., Litkouhi, B., Welch, W.R., Berkowitz, R.S., Mok, S.C., Garner, E.I. C-Terminus of Clostridium perfringens Enterotoxin Downregulates CLDN4 andSensitizes Ovarian Cancer Cells to Taxol and Carboplatin. Clin Cancer Research, 17(5):1065-1074. 2011.

[114] Agrawal, N., Bettegowda, C., Cheong, I., Geschwind, J.F., Drake, C.G., Hipkiss, E.L., Tatsumi, M., Dang, L.H., Jr. Diaz, L.A., Pomper, M., Abusedera, M., Wahl, R.L., Kinzler, K.W., Zhou, S., Huso, D.L., Vogelstein, B. Bacteriolytic therapy can generate a potent immune response against experimental tumors. Proceedings of the National Academy of Sciences U S A, 101(42):15172-15177, 2004.

[115] Galmbacher, K., Heisig, M., Hotz, C., Wischhusen, J., Galmiche, A., Bergmann, B., Gentschev, I., Goebel, W., Rapp, U.R., Fensterle, J. Shigella mediated depletion of macrophages in a murine breast cancer model is associated with tumor regression. PLoS One, 5(3):0009572, 2010.

[116] Mathur, D.D., Deshmukh, S., Kaushik, H., Garg, L.C. Functional and structural characterization of soluble recombinant epsilon toxin. Applied Microbiology and Biotechnology, 88(4):877-884, 2010.
[117] Chhabra, G., Sharma, P., Anant, A., Deshmukh, S., Kaushik, H., Gopal, K., Srivastava N., Sharma, N., Garg, L.C. Identification and modeling of a drug target for Clostridium perfringens SM101. Bioinformation 4(7):278-289. 2010.

[118] Kaushik, H., Deshmukh, S., Mathur, D.D., Tiwari, A., Garg, L.C. Recombinant expression of in silico identified Bcell epitope of epsilon toxin of Clostridium perfringens in translational fusion with a carrier protein. Bioinformation, 9(12):617-621, 2013.

[119] English, D.P., Santin, A.D. Claudins overexpression in ovarian cancer: potential targets for Clostridium. International Journal of Molecular Sciences, 14(5):10412-10 437, 2013.

[120] Kominsky, S.L., Vali, M., Korz, D., Gabig, T.G., Weitzman, S.A., Argani, P., Sukumar, S. Clostridium perfringens enterotoxin elicits rapid and specific cytolysis of breast carcinoma cells mediated through tight junction proteins claudin 3 and 4. American Journal of Pathology, 164(5):1627-1633, 2004.

[121] Milas, L., Wike, J., Hunter, N., Volpe, J., Basic, I. Macrophage content of murine sarcomas and carcinomas: associations with tumor growth parameters and tumor radiocurability. Cancer Research, 47(4):1069-1075, 1987.

[122] Kioi, M., Vogel, H., Schultz, G., Hoffman, R.M., Harsh, G.R., Brown, J.M. Inhibition of vasculogenesis, but not angiogenesis, prevents the recurrence of glioblastoma after irradiation in mice. Journal of Clinical Investigation, 120(3):694-705, 2010.

[123] Kozin, S.V., Kamoun, W.S., Huang, Y., Dawson, M.R., Jain, R.K., Duda, D.G. Recruitment of myeloid but not endothelial precursor cells facilitates tumor regrowth after local irradiation. Cancer Research, 70(14):5679-5685, 2010.

[124] Coffelt, S.B., Hughes, R., Lewis, C.E. Tumor-associated macrophages: effectors of angiogenesis and tumor progression. Biochimica Biophysica Acta, 1(1):11-18, 2009.

[125] Verreck, F.A., de Boer, T., Langenberg, D.M., Hoeve, M.A., Kramer, M., Vaisberg, E., Kastelein, R., Kolk, A., de Waal-Malefyt, R., Ottenhoff, T.H. Human IL-23-producing type 1 macrophages promote but IL-10-producing type 2 . Proceedings of the National Academy of Sciences U S A, 101(13):4560-4565, 2004.

[126] Biswas, S.K., Mantovani, A. Macrophage plasticity and interaction with lymphocyte subsets: cancer as a paradigm. Nature Immunology, 11(10):889-896, 2010.

[127] Krausgruber, T., Blazek, K., Smallie, T., Alzabin, S., Lockstone, H., Sahgal, N., Hussell T., Feldmann, M., Udalova, I.A. IRF5 promotes inflammatory macrophage polarization and TH1-TH17 responses. Nature Immunology, 12(3):231-238, 2011.

[128] Fleetwood, A.J., Dinh, H., Cook, A.D., Hertzog, P.J., Hamilton, J.A. GM-CSF- and M-CSF-dependent macrophage phenotypes display differential dependence on type I interferon signaling. Journal of Leukocyte Biology, 86(2):411-421, 2009.

[129] Donlin, L.T., Jayatilleke, A., Giannopoulou, E.G., Kalliolias, G.D., Ivashkiv, L.B. Modulation of TNF-induced macrophage polarization by synovial fibroblasts. Journal of Immunology, 193(5):2373-2383. 2014. 
[130] Saccani, A., Schioppa, T., Porta, C., Biswas, S.K., Nebuloni, M., Vago, L., Bottazzi, B., Colombo, MP., Mantovani, A., Sica, A. p50 nuclear factor-kappaB overexpression in tumor-associated macrophages inhibits. Cancer Research, 66(23):11432-11440, 2006.

[131] Guiducci, C., Vicari, A.P., Sangaletti, S., Trinchieri, G., Colombo, M.P. Redirecting in vivo elicited tumor infiltrating macrophages and dendritic cells. Cancer Research, 65(8):3437-3446. 2005.

[132] O' Farrell, A.M., Liu, Y., Moore, K.W., Mui, A.L. IL-10 inhibits macrophage activation and proliferation by distinct signaling. EMBO Journal, 17(4):1006-1018, 1998.

[133] Lang, R., Patel, D., Morris, J.J., Rutschman, R.L., Murray, P.J. Shaping gene expression in activated and resting primary macrophages by IL-10. Journal of Immunology, 169(5):2253-2263, 2002.

[134] Baltimore, D., Boldin, M.P., O' Connell, R.M., Rao, D.S., Taganov, K.D. MicroRNAs: new regulators of immune cell development and function. Nature Immunol, 9(8):839-845, 2008.

[135] Squadrito, M.L., Etzrodt, M., De Palma, M., Pittet, M.J. MicroRNA-mediated control of macrophages and its implications for cancer. Trends Immunology 34(7):350-359, 2013.

[136] Graff, J.W., Dickson, A.M., Clay, G., McCaffrey, A.P.,
Wilson, M.E. Identifying functional microRNAs in macrophages with polarized phenotypes. Journal of Biological Chemistry, 287(26):21816-21825, 2012.

[137] O' Connell, R.M., Rao, D.S., Chaudhuri, A.A., Boldin, M.P., Taganov, K.D., Nicoll, J., Paquette, R.L., Baltimore, D. Sustained expression of microRNA-155 in hematopoietic stem cells causes a myeloproliferative disorder. Journal of Experimental Medicine, 205(3):585-594. 2008.

[138] Taganov, K.D., Boldin, M.P., Chang, K.J., Baltimore, D. NF-kappaB-dependent induction of microRNA miR-146, an inhibitor targeted to signaling proteins of innate immune responses. Proceedings of the National Academy of Sciences U S A, 103(33):12481-12486, 2006

[139] Banerjee, S., Xie, N., Cui, H., Tan, Z., Yang, S., Icyuz, M., Abraham, E., Liu, G. MicroRNA let-7c regulates macrophage polarization. Journal of Immunology, 190(12):6542-6549, 2013.

[140] Rakiman, I., Chinnadurai, M., Baraneedharan, U., Paul, S.F.D., Venkatachalam, P. $\gamma$-H2AX assay: a technique to quantify DNA double strand breaks. Advanced Biotech, 7:39-41, 2008.

[141] Tripathi, K., Mani, C., Clark, D.W., Palle, K. Rad18 is required for functional interactions between FANCD2, BRCA2, and Rad51 to repair DNA topoisomerase 1-poisons induced lesions and promote fork recovery. Oncotarget, 7(11):12537-12553, 2016. 